\title{
Associations of physical activity and sedentary behaviors with dietary behaviors among mid- adolescent female students in the southeast of Iran
}

\author{
Fariba Shahraki-Sanavi ${ }^{1}$, Fatemeh Rakhshani ${ }^{2}$, Alireza Ansari-Moghaddam ${ }^{3 *}$ and \\ Mahdi Mohammadi ${ }^{4}$ \\ ${ }^{1}$ PhD Student Health Education \& Promotion, Health Promotion Research Center, Public Health Department, \\ Zahedan University of Medical Science, Zahedan, Iran \\ ${ }^{2}$ Professor Health Education, Safety Promotion and Injury Prevention Research Center (SPIPRC), Shahid \\ Beheshti University of Medical Sciences, School of Public Health, Tehran, Iran \\ ${ }^{3}$ Professor Epidemiology, Health Promotion Research Center, Epidemiology \& Biostatistics Department, \\ Zahedan University of Medical Sciences, Zahedan, Iran \\ ${ }^{4}$ Associate Professor in Statistic, Health Promotion Research Center, Epidemiology \& Biostatistics \\ Department, Zahedan University of Medical Sciences, Zahedan, Iran
}

\begin{abstract}
Given the complexity of dietary behaviors and physical activity of adolescents and its relationship to the chronic diseases later on, the present study aimed to investigate the relationship between the physical activity and sedentary behaviors with dietary behaviors of female high school students in the southeast of Iran. This cross-sectional study was conducted in four public high schools in the southeast of Iran (Zahedan) on a sample of 457 female students of Tenth Grade. Information collected using a self-reported 38-item questionnaire with the content validity ratio (CVR) of 0.79 , the content validity index (CVI) of 0.88 and the reliability $(\alpha)$ of 0.70 . The data were analyzed by SPSS15 Software by linear and logistic regression models. Physical activity and socio-economic class of students were predictors of their healthy dietary behavior. Students who had spent much time in sedentary behaviors were more likely to consume fast foods.It is recommended to implement some combined interventions including training, consultation and environmental supports in schools along with the focus on family intervention so as to strengthen and lengthen the effects of interventions.
\end{abstract}

KEY WORDS: PHYSICAL FITNESS, NUTRITION, TEENS

\section{ARTICLE INFORMATION:}

*Corresponding Author: ansaryalireza@yahoo.com Received $2^{\text {nd }}$ Nov, 2017

Accepted after revision 28 $8^{\text {th }}$ Dec, 2017

BBRC Print ISSN: 0974-6455

Online ISSN: 2321-4007 CODEN: USA BBRCBA

$\therefore$ Thomson Reuters ISI ESC and Crossref Indexed Journal

NAAS Journal Score 2017: 4.31 Cosmos IF: 4.006

${ }^{\circ}$ A Society of Science and Nature Publication, 2017. All rights reserved.

Online Contents Available at: http//www.bbrc.in/

DOI: $10.21786 / \mathrm{bbrc} / 10.4 / 20$ 


\section{INTRODUCTION}

Despite major plans of public health to increase the public awareness regarding the promotion of healthy dietary behaviors and physical activity of healthy people by 2020, these issues are still considered as major concerns of the public health. (America's Health Literacy: 2008) Nowadays, non-communicable diseases have been prevalent in both developed and developing countries. It has been well proven that poor dietary habits are directly associatedwith the outbreak of some serious health problems such as diabetes, cardiovascular diseases and probably some types of cancers in the future life ofthe adolescents. (Ogden et al 2012, Rao 2008).

In comparison, increased physical activity is related to the lower blood pressure, body fitness and blood fat regulation. It also reduces the depression and anxiety and increases self-esteem and quality of life. On the other hand, a decrease in the physical activity and increase in the sedentary activitiesare significantly associated with the risk of obesity, (Singh et al., Vuori 2010; Hills et al., 2006; Andersen et al., 2011; Kantomaa et al., 2008; Motl et al., 2004) cardiovascular health defects, (Ankoski et al. 2011; Healy et al 2011; Henson et al. 2013) and mortality. (León-Muñoz et al., 2013; Matthews et al. 2012).

Key indicator of bodily activity includes physical activity and activities with low mobility (sedentary activities), while dietary behavior includes the diet and the number of meals. (Jiménez-Pavón et al. 2011-Rodríguez et al., 2011).

The ideal diet for teenagers includes supplying needed calories by eating nutrient foods such as fruits, vegetables, dairy, whole grains, and low-fat protein and limiting the consumption of high-fat foods and beverages. Then, it is recommended for the teenagers to have healthy diet with eating at least five portions of fruits and vegetables a day and limiting fat intake to less than thirty percent of their energy needs, (Nelson et al., 2005) as well as having at least sixty minutes of moderate to severe physical activity most of the days of the week and participation of two hours or less per day in sedentary activities, (Sanchez et al., 2007).

However, some studies reported that only $30-40 \%$ of teenagers have at least sixty minutes of physical activity five times or more per week (Larsen et al. 2004) and the level of sedentary activities increases in their older age. (Driskell et al., 2008).

In addition, the nutritional trends suggest that most teenagers don't adhere to the recommended diet of servings five portions of fruits and vegetables a day, consuming dairy products two or more times a day, and having grains six times a daywhereas they may not eat breakfast regularly.In comparison, they may eat fast food two or more times a week. (Larson et al., 2008) On the other hand, nearly a quarter of their daily calorie is supplied by having sugary drinks, (Harrington 2008).
Data suggest that in recent years, there has not only been a decrease in the level of Iranian teenagers' physical activities, but their food tastes have also had a tendency towards the high-calorie foods and the foods lacking of nutritional value (Kelishadi et al. 2005).

However, healthy nutrition and regular physical activities which are parts of the health promoting behaviors can preventwasting of costs, causingmorbidity, and mortality (Lee and Loke 2005). Given the importance of healthy nutrition and physical activity to maintain and improve the public health, the currents study aimed to investigate the relationship between the physical activity and sedentary behaviors, and dietary behaviors of female high school students in the southeast of Iran (Zahedan) so as to assess the current status of the adolescent behaviors; then, the results can be used for planning of health promotion interventions in schools.

\section{MATERIAL AND METHODS}

The present cross-sectional school-based study was carried out in the South East of Iran (Zahedan) in 2015. First, 4 female state high schools were randomly selected; then, all students in Grade $10(n=457)$ wereenrolled in the study through a census. The objectives of the study and the way of answering the questionnaire were explained to the participants. The subjects were entered into the study with observing the ethical codes and voluntary. Data collected via a self-reported questionnaire including demographic questions (11 items), healthy dietary behaviors (14 items), physical activity and sedentary behaviors (7 items), thestatus of the school and description of the weight (6 items). The questionnaire has content validity ratio (CVR) of 0.79 , the content validity index (CVI) of 0.88 and the reliability $(\alpha)$ of 0.70 that examines the students' nutritional status and physical activity during the week before the study. The minimum and maximum scores for nutrition were 14 and 64, respectively; for the physical activity dimension,the minimum, and maximum scores were 7 and 47, respectively. The questionnaires did not include any identifying information and the students were explained that the information was solely analyzed in thegroup. The allocated time to complete the questionnaire was 15-20 minutes. After collecting the data, they were analyzedby SPSS15 Softwareusing the linear and logistic regression models.

\section{RESULTS}

The study includeda total of 457 teenage girls of $10^{\text {th }}$ Grade in the 14-17 age range and majority of them were at the birth rank of 1-3. Half of their fathers were employees and their education levels were around diploma. Most of their mothers were housewives and majority of them had the high school diploma as well. Table $1 \mathrm{dem}-$ 
Table 1 . The prevalence of dietary behaviors, Physical/sedentary activities and weightrelated Dietary behaviors

Student who did not eat fruit drink 100\% fruit juices

drank $100 \%$ fruit juices one to three day/week

drank 100\% fruit juices four to six day/week

drank 100\% fruit juices one times/day

drank 100\% fruit juices two or more times/day

Student who did not drink milk

drank milk one to three day/week

drank milk four to six day/week

drank milk one times/day

drank milk two or more times/day

Student who did not drink a can or glass of cola or other drank a can or glass of cola or other one to three day/week

drank a can or glass of cola or other four to six day/week

drank a can or glass of cola or other one times/day

drank a can or glass of cola or other two or more times/day

Student who did not drink a can or glass of energy/Sports drank

drank a can or glass of energy/Sports drank one to three day/week

drank a can or glass of energy/Sports drank four to six day/week

drank a can or glass of energy/Sports drank one times/day

drank a can or glass of energy/Sports drank two or more times/day

Student who did not eat fruit

ate fruit one or two day/week

ate fruit three to six day/week

ate fruit five to seven day/week

Student who did not eat vegetables ate vegetables one or two day/week ate vegetables three to six day/week ate vegetables five to seven day/week

Student who did not eat beef/lamb

ate beef/lamb one or two day/week

ate beef/lamb three to six day/week

ate beef/lamb five to seven day/week

Student who did not eat chicken/fish

ate chicken/fish one or two day/week

ate chicken/fish three to six day/week

ate chicken/fish five to seven day/week

Student who did not eat dairy products

ate dairy products one or two day/week

ate dairy products three to six day/week

ate dairy products five to seven day/week

Percent (95\% CI)

53.08(48.47-57.69)

$24.45(20.48-28.41)$

6.17(3.94-8.38)

12.11(9.10-15.12)

4.19(2.33-6.03)

35.90(31.47-40.33)

$35.24(30.83-39.65)$

$9.47(6.76-12.17)$

$14.54(11.28-17.79)$

$4.85(2.86-6.82)$

$47.80(43.18-52.40)$

$10.79(7.92-13.65)$

$6.83(4.49-9.15)$

$29.07(24.88-33.26)$

$5.51(3.40-7.61)$

90.52(87.82-93.23)

$5.50(3.40-7.61)$

$0.66(0.08-1.40)$

$2.20(0.84-3.55)$

$1.10(0.13-2.06)$

3.74(1.99-5.49)

$18.72(15.12-22.32)$

28.85(24.67-33.03)

48.68(44.06-53.29)

Student who did not eat sweets/chocolate

ate sweets/chocolate one or two day/week

ate sweets/chocolate three to six day/week

ate sweets/chocolate five to seven day/week

$13.44(10.28-16.58)$

40.31(35.77-44.83)

28.41(24.24-32.57)

$17.84(14.30-21.37)$

Student who did not eat nuts

ate nuts one or two day/week

ate nuts three to six day/week

$10.57(7.73-13.41)$

$29.52(25.30-33.72)$

$36.12(31.68-40.55)$

23.79(19.85-27.72)

7.93(5.43-10.42)

$34.80(30.40-39.20)$

$34.14(29.76-38.51)$

23.13(19.23-27.02)

5.95(3.76-8.13)

29.74(25.51-33.95)

25.77(21.73-29.80) 38.55(34.05-43.04)

ate nuts five to seven day/week

$10.35(7.53-13.16)$

24.67(20.68-28.65)

46.26(20.68-28.65)

18.72(15.12-22.32)

$18.94(15.32-22.56)$

39.21(34.69-43.71)

24.01(20.06-27.95)

17.84(14.30-21.37)

Student who did not eat goody

ate goody one or two days/week

ate goody three to six day/week

ate goody five to seven day/week

23.79(19.85-27.72)

$18.72(15.12-22.32)$

$39.87(35.34-44.38)$

17.62(14.10-21.13) 


\begin{tabular}{|c|c|}
\hline $\begin{array}{l}\text { Student who did not eat fast food } \\
\text { ate fast food one or two days/week } \\
\text { ate fast food three to six day/week } \\
\text { ate fast food five to seven day/week }\end{array}$ & $\begin{array}{l}40.31(35.77-44.83) \\
9.47(6.76-12.17) \\
42.73(38.16-47.29) \\
7.49(5.05-9.91)\end{array}$ \\
\hline $\begin{array}{l}\text { Students who did not eat breakfast } \\
\text { ate breakfast on all } 7 \text { days }\end{array}$ & $\begin{array}{l}11.45(8.51-14.39) \\
53.74(49.14-58.34)\end{array}$ \\
\hline Mean of Dietary behaviors (SD) & $43.69(6.20)$ \\
\hline Physical/sedentary activities & Percent $(95 \% \mathrm{CI})$ \\
\hline $\begin{array}{l}\text { Student who did not participate in at least } 60 \text { minutes of physical activity } \\
\text { participated in physically active at least } 60 \text { minutes/day on } 1 \text { or } 2 \text { days/week } \\
\text { participated in physically active at least } 60 \text { minutes/day on } 3 \text { or } 4 \text { days/week } \\
\text { participated in physically active at least } 60 \text { minutes/day on } 5 \text { or } 6 \text { days/week } \\
\text { participated in physically active at least } 60 \text { minutes/day on all } 7 \text { days }\end{array}$ & $\begin{array}{l}46.56(32.11-41.01) \\
41.85(37.29-46.40) \\
13.44(10.28-16.58) \\
3.96(2.16-5.76) \\
4.19(2.33-6.03)\end{array}$ \\
\hline $\begin{array}{l}\text { Student who did not participate in muscle-strengthening activities } \\
\text { participated in muscle-strengthening activities on } 1 \text { or } 2 \text { days/week } \\
\text { participated in muscle-strengthening activities on } 3 \text { or } 4 \text { days/week } \\
\text { participated in muscle-strengthening activities on } 5 \text { or } 6 \text { days/week } \\
\text { participated in muscle strengthening activities on all } 7 \text { days }\end{array}$ & $\begin{array}{l}50.00(45.38-54.61) \\
40.97(36.42-45.50) \\
4.41(2.51-6.30) \\
1.54(0.40-2.67) \\
3.08(1.48-4.67)\end{array}$ \\
\hline $\begin{array}{l}\text { Student who did not go to jam } \\
\text { went jam on } 1 \text { or } 2 \text { days/week } \\
\text { went jam on } 3 \text { or } 4 \text { days/week } \\
\text { went jam on } 5 \text { days/week }\end{array}$ & $\begin{array}{l}70.26(66.04-74.48) \\
21.59(17.78-25.38) \\
6.61(4.31-8.90) \\
1.54(0.40-2.67) \\
\end{array}$ \\
\hline $\begin{array}{l}\text { Student who did not play video or computer games or used a computer } \\
\text { played video or computer games or used a computer for } 1 \text { to } 2 \text { hours/day } \\
\text { played video or computer games or used a computer for } 3 \text { or more hours/day }\end{array}$ & $\begin{array}{l}49.34(44.72-53.95) \\
44.05(39.46-48.63) \\
6.61(4.31-8.90)\end{array}$ \\
\hline $\begin{array}{l}\text { Student who did not watch television } \\
\text { Student who watched } 1 \text { to } 2 \text { hours/day of television } \\
\text { Student who watched } 3 \text { or more hours/day of television }\end{array}$ & $\begin{array}{l}9.03(6.38-11.67) \\
55.95(51.36-60.53) \\
35.02(30.61-39.42)\end{array}$ \\
\hline $\begin{array}{l}\text { A student who did not use mobile (whats up, Viber, email, ...) } \\
\text { used mobile (whats up, Viber, email, ...) } 1 \text { to } 2 \text { hours/day } \\
\text { used mobile (whats up, Viber, email, ...) } 3 \text { or more hours/day }\end{array}$ & $\begin{array}{l}38.99(34.48-43.49) \\
37.00(32.54-41.46) \\
24.01(20.06-27.95)\end{array}$ \\
\hline Mean of Physical/sedentary activities (SD) & $22.49(4.84)$ \\
\hline \multicolumn{2}{|l|}{ Weight-related } \\
\hline Student who described themselves as Obese & 4.41(3.76-8.13) \\
\hline Student who described themselves as Overweight & $22.25(11.08-17.55)$ \\
\hline Student who described themselves as Normal weight & 53.08(48.47-57.69) \\
\hline Student who described themselves as low weight & $14.32(18.40-26.08)$ \\
\hline Student who described themselves as Underweight & $5.95(2.51-6.30)$ \\
\hline
\end{tabular}

onstrated the prevalence of dietary behaviors, Physical/ sedentary activities and weight related variables. As can be seen, teenagers who do not have all-natural juice and milk twice a day or more were about 4 and $5 \%$, respectively. Nearly half of them had fruits every day, $18 \%$ vegetables, 15\% milk and dairy products, and 18\% nuts. In addition, nearly half of the surveyed adolescents reported the least level of daily physical activity and stretching exercises. The percentage of adolescents who spend more than two hours a day for sedentary activities including working with the computer, watching $\mathrm{TV}$, using cell phones and social networks were about 35.7 and $24 \%$, respectively. Moreover, about 4\% of students reported to be overweight and 6\% reported severe weight loss.
The physical activity and socio-economic classeswere predictors of the healthy nutritional behavior (Table 2).

The results (Table 3) also showed that, there is a positive significant relationship between the consumption of fast foods and behaviors related to the physical activity in the studied high school students.

\section{DISCUSSION}

The findings of the present study illustrated that the majority of the studied adolescents do not have daily all-natural juiceand less than a quarter of them do not eat, milk. Almost half of them have daily breakfast, fruits and less than a quarter of them eatonce or more 


\begin{tabular}{|l|l|l|l|l|l|}
\hline \multicolumn{2}{|c|}{ Table 2. Linear Regression Test for the Prediction of Healthy Dietary Behaviors of the Studied Adolescents } \\
\hline $\begin{array}{r}\text { Independent } \\
\text { Variable }\end{array}$ & \multicolumn{2}{|c|}{$\begin{array}{c}\text { Unstandardized } \\
\text { Coefficients }\end{array}$} & $\begin{array}{l}\text { Standardized } \\
\text { Coefficients }\end{array}$ & t & P value \\
\cline { 2 - 8 } & B & Std.Error & Beta & & \\
\hline Physical/sedentary activities & 0.33 & 0.05 & 0.26 & 5.84 & 0.001 \\
\hline Family Economy & 0.99 & 0.38 & 0.11 & 2.56 & 0.01 \\
\hline
\end{tabular}

Table 3. Binary Logistic Regression for ate fast food with Sedentary-related behaviors

\begin{tabular}{|l|l|}
\hline Sedentary Behavior & Fast food OR $(95 \% \mathrm{CI})$ \\
\hline Watched TV $\geq 2$ hours per day & $\begin{array}{l}\text { Reference } \\
0.63(0.43-0.94)^{*}\end{array}$ \\
No & \\
\hline Used mobile (whats up, Viber, email, ...) $\geq 2$ hours per day & Reference \\
No & $0.55(0.36-0.84)^{* * *}$ \\
\hline Yes & \\
\hline $\begin{array}{l}\text { Played video or computer games or used a computer for something other than school } \\
\text { work } \geq 2 \text { hours on an average school day }\end{array}$ & Reference \\
No & $0.54(0.28-1.03)^{*}$ \\
\hline Yes & \\
\hline $\begin{array}{l}\text { Ate at least one meal or snack at a fast food restaurant } \geq 1 \text { day/week } \\
* \mathrm{p}<0.05 \\
* * \mathrm{p}<0.01\end{array}$ & \\
\hline
\end{tabular}

fizzy sugary drinks daily. Half of them do the least level of physical activity and stretching exercises and almost a third of them are engaged in sedentary activities. A quarter of them were overweight or obese. A statistical significant relationship was observed between the unhealthy nutrition and physical activity behavior and socio-economic classes of the student and between the fast food consumption and sedentary behaviors.

The results indicate that the removal of breakfast meal among the students ranged from 1.7 to $30 \%$ and having daily breakfast reported to be 31-33\%.The results also suggest the high level of not having breakfast in female students and its growing prevalence rate with the low socio-economic status and higher ages. Students who eat breakfast regularly, have healthier food choices and adolescents who go to school without having breakfast, their typical foods are chips, popcorn and sugary drinks. In this regard, the results of the present study are consistent with the previous ones.

Regarding the consumption of milk and dairy products at least 1-3 times a day, the consumption level has been reported to be $2-25.1 \%$ and lack of consumption of the same group reported to be 14.8 - $22.4 \%$; however, it has been reported that $98 \%$ of Swedish adolescents use milk and its products at least once a day. Similar to previous studies, the subjects in the present study, despite the daily distribution of milk in schools, use milk and dairy products at the lower level.
With respect to the consumption of fruits and vegetables, the results of previous studies indicate that 11.5 $-68.2 \%$ of adolescents in different countries have daily natural juices and fruits, and 11.6 - 58\% of them eat fruits and vegetables at least once or more a day. In a study in Iran, the mean frequency of the consumption of fruits and vegetables among the students were 1.2 and 1.1 times a day, respectively. In the present study, the consumption of natural juices was at the lower level, but due to the availability of fruits in Iran, almost half of the students have daily fruit consumption. However, like the previous studies, the consumption level of vegetables was at the lower level.

In the present study, the consumption of red and white meat was observed only in one quarter of the students. While the consumption level of red meat among the adolescents of Syrian and Swedish has been reported equal to $62 \%$ and $82 \%$ a day, respectively.According to other studies, high-protein diets containing red meat would also be resulted in weight control.

The results of studies reflect lower consumption of fruits, vegetables, fish, dairy products and eggs among adolescents; they also get more unhealthy foods like French fries, burgers, sugary drinks and a variety of jellies. Due to containing high sugar and energy, sodas cause to overweight and reduced consumption level of fruits, vegetables and dairy products. However, this relationship has not been seen in some studies. In the pre- 
sent study, half of the students had fizzy sugary drinks more than twice a day.

The prevalence of watching TV more than 2 hours a day among the American students showed a significant reduction from 43\% in 1999 to 32\% in 2013 and an increase to $43.3 \%$ in 2015 . There has also been an increase in the time allocated to using computer and playing video games from 22\% in 2003 to 43\% in 2015. In comparison, Iranian female adolescents were similar to American teenagers in this regard; however, the prevalence of reduction in the physical activity and sedentary behaviors in Jordanian adolescents was reported to be at higher level; and in European adolescents, the results showed that only 18\% of them have consistently healthy behaviors and 21\% of them had consistently unhealthy behaviors. The percentage of watching TV in the studied adolescents was similar to the results of above-mentioned studies, but the time spent on computer games was lower in this population.

The results indicate that nearly one- third of adolescents had daily fast food and nearly a quarter of them eat fast food more than three times a week; in the families with high income and residents of the North of the city, the level of fast food consumption was high. The results indicate that one of the factors influencing the food choices in adolescents is their socio-economic status. On the other hand, consumption of fast foods and a sedentary life style are among the factors of overweight in adolescents.Like the previous studies, fast consumption level was high. Furthermore, a significant relationship was observed between the socio-economic status of students and their orientation to unhealthy nutrition. In general, the role of the family's economic status on food choices can be justified due to the increased purchasing power and access to a variety of foods.

The prevalence of overweight in female Asian teens was reported $6.2-18.9 \%$ and the obesity $1.8-4.7 \%$; the overweight in adolescents of Spain, Mexico, Ecuador, Jordan, Taiwan, the U.S, and New Zealand has been reported to be $8.3-26.6 \%$ and the obesity $3.9-18 \%$. The results showed that the prevalence of overweight or obesity among the Filipino teens has had a reduction from $11.4 \%$ in 2003 to $9.4 \%$ in 2011. Similar description of weight with Asian teens has been reported in the present study by our participants.

The results demonstrated a relationship between the sedentary behaviors and less healthy diet. The adolescents who watch TV more than 5 hours a day and don't exercise are more likely to consume fast foods.The present study also showedthat adolescents with more sedentary activities have more chances to use fast foods. Said the reasons for this might be the fact that adolescents who watch TV more and have less physical activity are more inclined to the advertised foods and they normally eat more food while watching TV.
According to the results and since the health promotion of this age range can be effective in the prevention of non-communicable diseases in the developing countries, it's recommended to establish the necessary measures to comply with the principles of healthy lifestyle habits, because subsequent attempts to change the established habits will be very difficult and perhaps impossible. On the other hand, given the importance of the family in Iran and due to the emotional and financial dependency of adolescents to families in this age range, the strong impact of family support on physical activity and dietary behaviors of students is logical. Therefore, designing training programs with an emphasis on the central role of the family can be effective in the promotion of healthy dietary behaviors and doing physical activities in this age group. Therefore, it's also necessary to design and implement interventions based on behavior change for adolescents in the schools.

\section{LIMITATION}

Students participated in this study were limited to the public schools and grade 10, therefore, are not representative of all adolescents in this age group. In addition, the data collected are based on a self-administered questionnaire.

\section{ACKNOWLEDGMENTS}

This article was part of the Ph.D. dissertation. The Study was funded by Zahedan University of medical science with grant number 2772 and ethical number IR.ZAUMS. REC.1394.251. Therefore, authors would like to express their gratitude to the Zahedan University of Medical Sciences, the Health Promotion Research Center, the District Department of Education and the school heads, teachers and students who helped conduct this study.

\section{CONFLICT OF INTEREST}

The authors declare that they have no conflict of interest.

\section{AUTHORS CONTRIBUTIONS}

The overall implementation of study design, data management and analysis and manuscript preparation were the results of join efforts by multiple individuals who are listed as coauthors of this paper. All authors read and approved the final manuscript.

\section{REFERENCES}

America's Health Literacy: 2008 Why We Need Accessible Health Information. 2008 ed. An Issue Brief From the U.S. Department of Health and Human Services; 
Andersen LB, Riddoch C, Kriemler S, Hills A.2011 Physical activity and cardiovascular risk factors in children. British journal of sports medicine. 45(11):871-876.DOI: 10.1136/bjsports-2011-090333 PubMed

Bankoski A, Harris TB, McClain JJ, 2011 et al. Sedentary activity associated with metabolic syndrome independent of physical activity. Diabetes care. 4(2):497-503.DOI: 10.2337/dc100987 PubMed

Driskell M-M, Dyment S, Mauriello L, Castle P, Sherman K. 2008 Relationships among multiple behaviors for childhood and adolescent obesity prevention. Preventive medicine. 46(3):209-215.D0I: 10.1016/j.ypmed.2007.07.028 PubMed

Gordon-Larsen P, Nelson MC, Popkin BM 2004 . Longitudinal physical activity and sedentary behavior trends: adolescence to adulthood. American Journal of preventive medicine. 27(4):277-283.DOI: 10.1016/j.amepre.2004.07.006 PubMed

Harrington S.2008 The role of sugar-sweetened beverage consumption in adolescent obesity: a review of the literature. The Journal of School Nursing. 24(1):3-12.DOI: 10.1622/10598405(2008)024[0003:TROSBC]2.0.C0;2 PubMed

Healy GN, Matthews CE, Dunstan DW, Winkler EA, Owen N. 2011 Sedentary time and cardio-metabolic biomarkers in US adults: NHANES 2003-06. European heart journal. ehq451. DOI: 10.1093/eurheartj/ehq451 PubMed

Henson J, Yates T, Biddle SJ, et al. 2013 Associations of objectively measured sedentary behaviour and physical activity with markers of cardiometabolic health. Diabetologia. 56(5):10121020.DOI: $10.1007 /$ s00125-013-2845-9 PubMed

Hills AP, Byrne NM. 2006 State of the science: a focus on physical activity. Asia Pac J Clin Nutr. 15(sSuppl).PMID: 16928660 PubMed

Jiménez-Pavón D, Ruiz JR, Ortega FB, 2011 et al. Physical activity, fitness and fatness in children and adolescents. Epidemiology of obesity in children and adolescents: Springer; 2011:347-366.

Kantomaa MT, Tammelin TH, Ebeling HE, Taanila AM. 2008 Emotional and behavioral problems in relation to physical activity in youth. Medicine and Science in Sports and Exercise. 40(10):1749-1756.DOI: 10.1249/MSS.0b013e31817b8e82 PubMed

Kelishadi R, Ardalan G, Gheiratmand R, et al. 2005 Do the dietary habits of our community warrant health of children and adolescents now and in future? CASPIAN Study. Iranian journal of pediatrics. 15(2):97-109.

Larson NI, Neumark-Sztainer DR, Story MT, Wall MM, Harnack LJ, Eisenberg ME. 2008 Fast food intake: longitudinal trends during the transition to young adulthood and corre- lates of intake. Journal of Adolescent Health. 43(1):79-86.DOI: 10.1016/j.jadohealth.2007.12.005 PubMed

Lee RL, Loke AJ. 2005 Health-promoting behaviors and psychosocial well-being of university students in Hong Kong. Public health nursing. 22(3):209-220.DOI: 10.1111/j.07371209.2005.220304.x PubMed

León-Muñoz LM, Martínez-Gómez D, Balboa-Castillo T, LópezGarcía E, Guallar-Castillón P, Rodríguez-Artalejo F. 2013 Continued sedentariness, change in sitting time, and mortality in older adults. Medicine and science in sports and exercise. 45(8): 1501-1507.DOI: 10.1249/MSS.0b013e3182897e87 PubMed

Matthews CE, George SM, Moore SC, 2012 Amount of time spent in sedentary behaviors and cause-specific mortality in US adults. The American journal of clinical nutrition. 95(2):437-445.DOI: 10.3945/ajcn.111.019620 PubMed

Motl RW, Birnbaum AS, Kubik MY, Dishman RK.2004 Naturally occurring changes in physical activity are inversely related to depressive symptoms during early adolescence. Psychosomatic Medicine. 66(3):336-342.PMID: 15184692 PubMed

Nelson MC, Gordon-Larsen P, Adair LS, Popkin BM. 2005 Adolescent physical activity and sedentary behavior: patterning and long-term maintenance. American journal of preventive medicine. 28(3): 259-266. DOI: 10.1016/j.amepre.2004.12.006 PubMed

Ogden CL, Carroll MD, Curtin LR, Lamb MM, Flegal KM. 2010 Prevalence of high body mass index in US children and adolescents, 2007-2008. Jama.303(3):242-249. DOI: 10.1001/jama. 2009. 2012 PubMed

Rao G. 2008 Childhood obesity: highlights of AMA Expert Committee recommendations. Am Fam Physician. 78(1):56-63. PMID: 18649611 PubMed

Rodríguez G, Sjöberg A, Lissner L, Moreno LA.2011 Food patterns and nutrient intake in relation to childhood obesity. Epidemiology of obesity in children and adolescents: Springer; 329-346.

Singh GK, Kogan MD, Van Dyck PC, Siahpush M. 2008 Racial/ ethnic, socioeconomic, and behavioral determinants of childhood and adolescent obesity in the United States: analyzing independent and joint associations. Annals of epidemiology. 18(9):682-695.D0I: 10.1016/j.annepidem.2008.05.001 PubMed

Sanchez A, Norman GJ, Sallis JF, Calfas KJ, Cella J, Patrick K. 2007 Patterns and correlates of physical activity and nutrition behaviors in adolescents. American journal of preventive medicine. 32(2):124-130.DOI: 10.1016/j.amepre.2006.10.012 PubMed

Vuori I. 2010 Physical activity and cardiovascular disease prevention in Europe: an update. Kineziologija. 42(1):5-15. 